\title{
Corporate Governance and the Sustainable Development
}

\author{
Prof. Bistra Boeva \\ $\mathrm{PhD}$, Stela Zhivkova \\ Assoc. prof. Ivan Stoychev \\ University for National and World Economy, Bulgaria
}

\begin{abstract}
Nowadays the issues of sustainable development are everywhere around us. Everybody talks about sustainability in all aspects of our life. It is becoming also part of the agenda of the business world not only for the small and medium size companies, but also for the big corporations. Gradually environmental and social issues begin to pose new topics in the agenda for board meetings of the big corporations. The corporate governance begins to pay more and more attention not only to the return rate of the investments but also to the footprint that the company has on the society. In this framework we decided to examine the relationship and interconnectivity between corporate governance and sustainable development. The research that backed this paper encompasses literature survey and analysis, on one hand and empirical research on another. This paper present some of the results from our survey showing the changes that occur in the corporate governance and the position of the managing boards of directors due to the sustainable development policy applied worldwide.
\end{abstract}

Keywords: sustainable development, corporate governance, corporate social responsibility, environment, governance

\section{Introduction}

In our contemporary business world, we observe quite a big diversity of business relationships and activities. This is mostly due to the intensive globalization processes worldwide. Globalization might be determined as a process of intercontinental economic, social and political integration. This integration allows companies to sell their products anywhere in the world and to have easier access to human and material resources (Wells, Shuey, Kiely, 2001). Globalization according to J. Stiglitz includes many things such as international exchange of knowledge and ideas, exchange of cultures, global environmental activities, economic globalization. The economic globalization in particular is the one where greater integration among the countries worldwide has been achieved through increased exchange of goods and services, capitals and even human resources (Stiglitz, 2002).

The globalization processes are caused mainly by the rapid development of technology and the drive to achieve rapid economic growth. These results in constant decrease of natural resources used as raw materials in manufacturing processes; climate change, leading to various natural disasters; disappearing biodiversity; decreasing amounts of drinking water. Within this context the main problem is no longer how to achieve economic growth and high living standards of the people but how to do it without ruining the planet? That's where comes the concept of the sustainable development and all the activities taken internationally.

In this context we decided to see how the modern trends related to the sustainable development are incorporated on company level. This is mainly responsibility of the companies' managers and is done by the companies' social policy. On the next pages briefly are presented some of the results from a scientific project called "Corporate governance and global supply chains within the sustainable development context".

\section{Sustainable development and its main characteristics}

The sustainable development nowadays is extremely relevant and discussed issue. There is a variety of definitions for sustainable development and its characteristics. 
The most widely used definition is the one given in the report entitled "Our Future" developed in 1987 by the World Commission on Environment and Development, led by Gro Brundtland, better known as the Brundtland Report. According to this report, sustainable development is "the one that satisfies the needs of the present without jeopardizing the ability of future generations to meet their needs.

The concept of sustainable development is built on the three most important aspects in the life of every society - economic development, social equity and environmental protection ${ }^{1}$. In the context of sustainable development, these fundamental aspects are called "pillars". Graphically they can be represented as follows2:

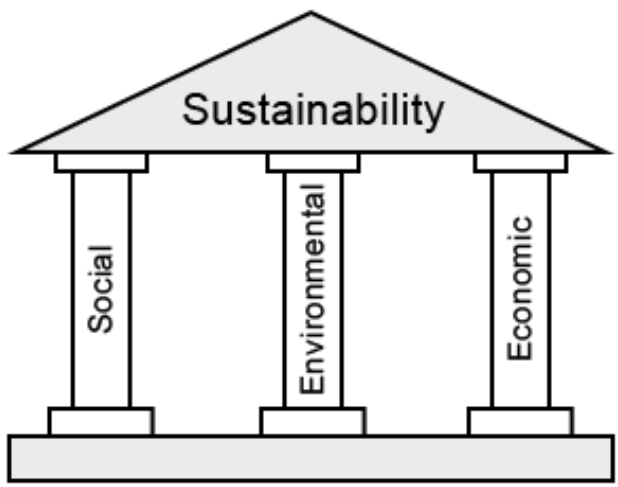

Sourse: www. thwink. org

This definition as well as its main principles allows making the conclusion that the main characteristic of the sustainable development is to achieve development of the society and its economic life in harmony with nature.

\section{Sustainable development and corporate governance}

The definition and characteristics of the sustainable development, briefly presented in the previous section, call for building a society where there is a balance between the economic, environmental and social goals. In order to achieve this goal, all three dimensions of sustainable development must be fulfilled. The integration of these three dimensions should be a condition for achieving a long-term corporate sustainability. However, this definition creates some difficulties for its practical application on company level. The description is quite common and provides very little guidance on the way companies should identify the current and the future needs as well as the technology and resources by which to meet these needs and to understand how to effectively balance their organizational responsibilities ${ }^{3}$.

The economic pillar of sustainable development is the most comprehensive and best applied by companies. They relate it mainly to production or production costs. What sometimes is not so clear are the other two pillars - environmental and social. At the level of a manufacturing enterprise the environmental sustainability refers to the use of energy and other resources and the footprint, which the company leaves as a result of its activities. Sustainable development in the field of environment is often related to waste reduction, pollution reduction, energy efficiency, reduce the air emissions, reduce the consumption of hazardous/ toxic materials, reduce the frequency of environmental accidents etc. Gimenez, Sierra, Rodon, 2012). Sustainable development in its social element shifts the focus to internal communities (for example the employees) and the society (Pullman et al. , 2009). Social sustainability means that companies (and manufacturing plants) provide equal opportunities, foster diversity, encourage social contacts within and outside the company and guarantee the quality of life of its employees.

Sustainability can also be defined as the strategy of the sustainable development process. Corporate Sustainability is seen as the ability of the company, by its management practices and market presence, to positively affect the ecosystem (improvement of natural resources, reducing pollution levels, etc. ), the community (support of the local population, creating

\footnotetext{
1 http://www.worldbank.org/depweb/english/sd.html

2 http://www.thwink.org/sustain/glossary/ThreePillarsOfSustainability.htm

${ }^{3}$ OECD, Principles of Corporate Governance, OECD, Paris, 2015
} 
jobs, etc. ) and the economic development (distribution of income through dividend payment of fair wages, etc. ). There can be sustainability of the company also when it creates value for its shareholders by maximizing the positive and minimizing the negative effects on environmental, social or economic issues (Krechovská M. , Prochazkova P. , 2014).

\section{Corporate governance and Corporate social responsibility}

Corporate governance is usually defined as "procedures and processes which provide the grounds for management and control of an organization"1. Corporate governance includes the activities of the Management Board (board of directors) and its relationship with shareholders, managers, but also with external parties such as auditors, regulatory authorities and other corporate participants. The structure of corporate governance determines the distribution of rights and responsibilities between the different parties in the company and sets the decision-making rules and procedures. In general the management board is the body that decides how the company will develop and how this will happen (Krechovská M. , Prochazkova P. , 2014).

There is an ongoing debate about the meaning and application of sustainable development in a business context. It is determined in different ways. One of the definitions is that "it is a creation of sustainable organizations through integrated economic, social and ecological systems" (Bansal, 2010). In a broad sense, the sustainability of a company means examining its development over time, taking into account its commitment to a healthy environment, economic and social systems so that the company can be more stable and resistant both to internal and external shocks (Ahi P. , Searcy C. , 2013). Sustainability issues receive increasing attention among businesses. The literature survey provides evidence that the paradigm of corporate governance has shifted progressively toward contemporary social issues (e. g. climate change, labor rights and corruption) (Walls, Berrone and Phan, 2012). There are various business initiatives promoting sustainability in different forms, but they most often are closely related to "corporate social responsibility". Most authors explore the corporate social responsibility (CSR) as a unit for measuring these functions (Walls, Berrone and Phan, 2012). Unfortunately, both the understandings and statements of international institutions (EC Green Paper on CSR), and some observations by academia representatives do not go beyond the essence of CSR and its relationship with variables of corporate governance such as investors, stakeholders, remuneration, committees (upon Boeva, 2015). The fundamental concept of A. Carrol (CSR pyramid) does not go beyond the 4 norms that the companies have to comply with: economic, legal, ethical and philanthropic (Carrol, 1991). Current studies reveal that CRS initiatives go beyond the formal reach of organizations (Mason and Simmons, 2014). The socially responsible suppliers and logistics are also considered. CSR is becoming an important topic on the agenda of corporate boards, on the one hand and indicates the relationship between corporate governance, corporate social responsibility and sustainable development (Clarke, 2007). Good corporate governance encompasses measures that address environmental and social issues (Masson and Machony, 2007). This view echoes the statement that global CSR is all about thinking and acting in socioeconomic categories (Eder and Oettingen, 2008). International business school defines CSR as the responsibility of corporations to meet the objectives of society (Dunning, 2008). In most cases, sustainable development and corporate social responsibility (CSR) are used as synonyms in the corporate context (Van Marrewijk, 2003). In fact, most of the companies develop and implement corporate social responsibility (CSR) as a way to meet the modern requirements for sustainability and simultaneously to improve their social reputation.

Corporate reputation is defined as "a set of attributes attached to company and defined on the bases of the company's past actions". The reputation of a company "provides information to the society about how its products, jobs, strategies and prospects are compared with those of its competitors" (Hoejmose St. , Roehrich J. , Grosvold J. , 2014). Moreover, company's reputation can be associated to its financial performance, the behavior of its stakeholders and its customers' trust.

\section{Corporate governance and environmental behaviour}

One of the main activities related to the companies' responsible and sustainable behavior, which is also embedded in their corporate social responsibility, is the voluntary disclosure (provision) of information both to the stakeholders and to the whole society. Why should the companies voluntarily disclose information concerning their environmental (sustainable) behavior? Some authors believe (Clarkson et al. , 2008) that companies with good environmental behavior would like to disclose this information in order to gain a competitive advantage over companies that have poor performance in terms of

1 OECD, Principles of Corporate Governance, OECD, Paris, 1999 
environment protection. These companies use different indicators and assess how their behavior towards nature will be accepted by society and based on the results of this evaluation decide whether to announce their activities in the field of environment protection or not ${ }^{1}$.

Socio-political theories present different perspective to the disclosure of information about the companies' environmental performance. According to the stakeholder theory the disclosure of information on activities in the field of environment protection is done because this information is requested by the stakeholders, in most cases, these are the shareholders (Cong Yu, Freedman M. , 2011). The company management meets these requirements by providing what it believes the stakeholders want to see and presents information about the company's environmental footprint. In most cases this is information about the pollution caused by the company.

According to the legitimacy theory, companies are trying to behave in a way that society wants them to behave. By disclosing information about its ecological behavior, the company legitimizes itself to the public thus relieving the public pressure. At the same time the company might act in a way completely different from what it has announced to the society. The main difference between the two theories is that in the the first one the company respondes by providing information that the management believes is what the shareholders want. In the legitimacy theory the information is provided by the management with the purpose to make the company look good in the eyes of society, but this information is not necessarily true.

In terms of environmental performance Cong and Friedman (2011) examine several studies proving that some of the corporate governance aspects influence on whether the companies break the environmental laws or not. Four aspects of the corporate governance have been discussed: how big is the management board, what is its composition, external management and internal property (Kassinis, Vafeas, 2002). Although the authors claim that both boards with many members and boards with a much smaller number of members may lead to fewer violations in terms of environmental protection, empirical evidence indicates that companies with smaller number of members in their management board have better environmental performance. They explain this phenomenon with the fact that board with many members is more likely to suppress the free exchange of ideas and in such a situation opportunistic executives can benefit.

Kassinis and Vafeas (2002) examine the composition of the board of directors as a factor for applying an environmental policy in the company. They believe that when the board is comprised of directors with close relations with the company this results in bigger damage for the environment. This means that when the management board members of a company are more familiar and connected to the production processes, they are more inclined to support executives that tolerate negligence of the environmental element in the sustainable development concept.

The authors examine the external management on the bases of in how many companies' boards a manager is a member. They claim the reputation of outside executives is an important factor that affects in how many boards of directors a manager will be invited to participate. In this respect, the external managers prefer to follow and enforce a policy of environmental protection in the operations of the companies where they are board members. Otherwise an illegal behavior might ruin their reputation.

Finally, the authors empirically prove that the larger shares of the company the directors have, the more inclined they are to tolerate violations of the environmental laws. This is true as in this situation their aim would be to get a higher return on their shares and it is worthy to take the risk of being caught violating the environmental laws.

\section{Good practice}

Activities related to corporate and product carbon footprint have gained popularity thanks to initiatives such as "Project for disclosure of information on carbon emissions" as well as the availability of new standards and guidelines including Publicly available specifications 2050 and the Protocol on greenhouse gas (PriceWaterhouseCoopers, 2012). The provision of information to investors and other stakeholders, including the general public on the generated emissions has reached the highest levels ever (Bartelmus P. , 1994). Leading companies integrate factors related to climate change in their business strategy (both short- and long-term). This is motivated mainly by: the presence of legal requirements (existing and expected); the desire to reduce costs and to improve the brand; new revenue opportunities; pressure from the stakeholders;

${ }^{1}$ Clarkson, P. M., Li, Y., Richardson, G. D., \& Vasvari, F. P. (2008). Revisiting the relation between environmental performance and environmental disclosure: An empirical analysis. Accounting, Organizations and Society 
customer behavior and risk of reputation loss (Skelton, 2013). This process includes also putting pressure on their suppliers. For example, the program for providing information on the carbon footprint on the supply chain (comprising 49 companies, including Wal-Mart, PepsiCola, Unilever and Dell) puts a requirement that forces the suppliers to disclose information about the emissions they generate (Pearce D. W. et all. , 1990). Most of the companies within this Program already reward their sub-contractors that implement processes for reduction of the carbon emissions and reject those that do not apply such activities (Accenture, 2012).

\section{Shareholders and the sustainable development - socially responsible investors}

Corporate governance is strengthened through actions for shareholders protect. The global financial crisis of 2007 revealed the behavior of the shareholders, mostly institutional investors, which demonstrates a lack of interest in the corporate governance of the companies they invest in. The reason for this behavior and the explanations of what causes it was clear: a policy of "short-termism" due to ongoing transactions with bonds and short-term "detention" of institutional investors in one company. Criticism was directed against the non-engagement of those investors in the corporate governance of the company. In search for opportunities for "engagement" of these shareholders a number of measures have been taken such as development of the Stewardship Code, European Commission's Action Plan for improving the company law and corporate governance dated 12/12/2012 etc.

The commitment has been combined with the compliance with the responsible investment rules, meaning that the shareholders as institutional investors begin to determine the agenda for sustainable development of the corporate management.

\section{1. Investors and the Principles for Responsible Investment (PRI) Initiative}

In close relation with the initiatives for larger involvement of the investors with the sustainable development issues are the six principles developed under the Principles for Responsible Investment (PRI) Initiative. What are these principles:

We include the environmental, social and governance issues /ESG/ in the financial analysis and in the decision making process.

We will be responsible owners and we will include the environmental, social and governance issues /ESG/ in our policy.

We will require disclosure of information about the environmental, social and governance issues /ESG/ from the companies we invest in.

We will encourage the application of these principles in the investment industry.

We will work together in order to improve the effectiveness from the application of these principles

We will disclose information about the application progress of these principles.

Those principles prove the changes in the approach of institutional investors regarding the companies where they invest. Responsible investment relies on the ability or the prerequisite for achieving long-turn and sustainable returns based on the acceptance and compliance of the environment protection policies, establishment of effective social system and governance. Following such policy of responsible investing means that there already is a new approach to analysis, investment decisions and engagement of the shareholders.

It should be mentioned that the shareholders have great contribution to the change in the corporate governance paradigm - from policy targeted to the stakeholders towards policy aimed at achieving sustainable development.

Further it is important to note the searched change in the policy of the shareholders that own significant parts of the large companies and their influence on the work of the corporate managers.

Last but not least, taking in mind the participants in the Principles for Responsible Investment (PRI) Initiative, it can be concluded that these are principles that influence the policy of corporate governance at the transnational companies (TNC) and above all their status of global companies.

Based on the above it could be concluded that these principles might be seen as a prerequisite for a stable financial system. They are also accepted by the banking community which has approved the Equator principles. 


\section{2. Black Rock case-study}

This institutional investor is a participant in the Principles for Responsible Investment (PRI) Initiative and voluntarily has agreed to follow these principles in its business. In particular, as of 31. 12. 2013 it invests and manages $6 \%$ of its portfolio - 249 US $\$$ in accordance with those rules. These are investments in economic sectors sensitive to the environmental issues. It is interesting to indicate the change in the company's investment process and in particular:

they include factors related to the environmental and social issues as well as the governance aspects /ESG/ in their investment analysis. They apply also their own rating system to the potential investor;

they evaluate the risks related to the environment, the social aspects and the governance in their investment analysis;

they have a committed behavior as an investor: during meetings, requests for information and control over the activities of the corporate management in compliance with the environmental, social and governance aspects;

they have evaluation and feedback.

These changes in the company's behavior show the commitment of its shareholders to the corporate governance issues including the policy of sustainable development.

Based on the above we can conclude that the changes in corporate governance are associated with one of its basic principles: the shareholders and their readiness to participate in these processes. The owners are the ones who direct and control the activities of the companies towards the sustainable development policy.

\section{Conclusion}

It is undisputable fact that the sustainable development has entered our life and caused quite a lot of things to change. Maybe one the most important changes that should be mentioned is the way the business world begins to work and think. As seen from the above pages the companies, especially the big transnational corporations started taking seriously the sustainable development issues. What has changed is that the management boards and the executives began bearing in mind the sustainability issues in all their activities. The return rates of the companies' share and the dividends are no longer the only thing that matters for the managers. For different reasons they incorporate the sustainable development policy, in all its three dimensions, into the corporate governance. Most of the companies nowadays have developed a corporate social responsibility policy and make quite a lot of efforts to communicate it to the public. The most popular aspect of the sustainable development is the environmental pillar. This is the field where the society is most sensible and that's where the efforts of the companies are directed. They tend to prove that they are environmentally responsible thus preserving their reputation on one hand and striving to get new clients on the other. That's why the boards of directors are more and more interested in the environmental performance of their companies and the executives are forced to manage the companies in more environmental friendly way and to disclose information on these issues.

Furthermore, the sustainable development policy has led to the emergency of the "socially responsible investors". They are investors that follow closely the work of the companies they invest in and are very much interested on their sustainable development performance. Prove for that is the Principles for Responsible Investment (PRI) Initiative with its six main principles to be followed by the investors.

All these changes in the corporate governance world undoubtedly show that the sustainable development is not just something written on paper and a "good wish". They illustrate that the efforts for preserving our planet already give results. It is obvious that the mindset of the business leaders, of the "people with money" has begun to change and getting profits and more money is no longer the only leading principle in the corporate governance world. The sustainable development ideas have entered there as well and have the potential to improve this world for the better. 


\section{References:}

[1] Accenture, 2012. CDP Supply Chain Report 2012. Carbon Disclosure Project. Accenture, New York, USA, London, UK

[2] Ahi P. , Searcy C. , 2013, A comparative literature analysis of definitions for green and sustainable supply chain management, Journal of Cleaner Production 52

[3] Bartelmus P. , 1994, Environment, Growth, and Development: The Concepts and Strategies of Sustainability, Routledge

[4] Bansal, T. , 2010. Network for Business Sustainability. http://nbs. net/wpcontent/uploads/Primer_Business_Sustainability. pdf

[5] Boeva B. , 2015. Corporate Governance and Global Supply Chains: How Self -regulation Replaces the Lack of Regulatory Initiatives or Do Regulatory Initiatives Add Value to Corporate Governance. Economic Alternatives, Issue 4

[6] Carroll, A. , 1991. Corporate Social Responsibility: Toward the Moral Management of Organizational Stakeholders, Business Horizons, July-August

[7] Clarkson, P. M. , Li, Y. , Richardson, G. D. , \& Vasvari, F. P. 2008. Revisiting the relation between environmental performance and environmental disclosure: An empirical analysis. Accounting, Organizations and Society, 33 (4-5), 303-327.

[8] Clarke, Th. , 2007. International Corporate Governance research, Routledge

[9] Cong Yu, Freedman M. , 2011, Corporate governance and environmental performance and disclosures, Advances in Accounting, incorporating Advances in International Accounting, 27 (2011) 223-232

[10] Dunning, J. , 2008. Corporate Social Responsibility: An Institutional Perspective

[11] Eder, Chr., M. Oettingen, 2008. The Business Case for Global CSR, in Business and Poverty, Innovative Strategies for Global CSR, ICEP, CODECA, V.

[12] Gimenez C. , Sierra V., Rodon J., 2012, Sustainable operations: Their impact on the triple bottom line, Production Economics 140 (2012), 149-159

[13] Hoejmose St. , Roehrich J. , Grosvold J. , 2014, Is doing more doing better? The relationship between responsible supply chain management and corporate reputation, Industrial Marketing Management 43 (2014) $77-90$

[14] Kassinis, G. , Vafeas K. 2002. Corporate boards and outside stakeholders as determinants of environmental litigation. StrategicManagement Journal, 23, 399-415

[15] Krechovská M. , Prochazkova P. , 2014, Sustainability and its Integration into Corporate Governance Focusing on Corporate Performance Management and Reporting, Procedia Engineering 69 (2014), 1144 - 1151

[16] Mason Chr. , J. Simmons, 2014. Embedding Corporate Social Responsibility in Corporate Governance approach, Journal of Business Ethics

[17] Masson, M. , J. O. Machony, 2007. Post traditional Corporate Governance, Governance and Sustainability, Working Paper Series, LSE

[18] Pearce D. W. , Barbier E. B. , Markandya A, 1990, Sustainable Development: Economics and Environment in the Third World, (Edward Elgar Pub

[19] Pullman, M. E. , Maloni M. J. , Carter C. G. , 2009. Food for thought: social versus environmental sustainability programs and performance outcomes. Journal of Supply Chain Management 45 (4), 38-54. 
[20] PriceWaterhouseCoopers, 2012. CDP Global 500 Climate Change Report 2012. PriceWaterhouseCoopers, London.

[21] Skelton A. , 2013, EU corporate action as a driver for global emissions abatement: A structural analysis of EU international supply chain carbon dioxide emissions, Global Environmental Change 23 (2013) 1795-1806

[22] Stiglitz J. , 2002, Globalization and Its Discontents, W. W. Norton \& Company

[23] Van Marrewijk, M. , 2003. Concepts and definitions of CSR and corporate sustainability: between agency and communion. Journal of Business Ethics 44 (2), 95-105.

[24] Walls, J. , P. Berrone, Ph. Phan, 2012. Corporate Governance and Environmental performance: is there really a link? Strategic Management Journal

[25] Wells G. , Shuey R. , Kiely R. , 2001, Globalization, Nova Science Publishers, Inc.

[26] http://www. worldbank. org/depweb/english/sd. html

[27] http://www. thwink. org/sustain/glossary/ThreePillarsOfSustainability. htm

[28] OECD, Principles of Corporate Governance, OECD, Paris, 2015 